\title{
Tensiones de la paternidad y la masculinidad en el cine negro argentino (1946-1952)
}

\author{
(4) Daniel Giacomelli \\ Consejo Nacional de Investigaciones Científicas y Técnicas / TECC - \\ Facultad de Arte - UNICEN, Argentina \\ daniel.giacomelli1@gmail.com
}

Recibido: 5/8/2020. Aceptado: 20/11/2020.

\begin{abstract}
Resumen
Analizaremos en El ángel desnudo (Carlos Hugo Christensen, 1946), El crimen de Oribe (Leopoldo Torres Ríos y Leopoldo Torre Nilsson, 1950), La bestia debe morir (Román Viñoly Barreto, 1952) y La encrucijada (Leopoldo Torres Ríos, 1952) una serie de elementos que problematizan la paternidad a través de argumentos afines al cine negro. Si bien la familia es una noción prevalente en los argumentos de las películas realizadas desde antes del inicio de la etapa industrial del cine argentino, nuestra intención es inspeccionar sus reconfiguraciones en un género de carácter crítico-social como lo es el cine negro, a la vez que reconocemos su connotación particular con respecto a la desintegración de las familias y las identidades masculinas y femeninas. Tendremos en cuenta la manera en la que en los films influyen, por un lado, el debate contemporáneo acerca de la crisis de la familia nuclear tradicional, en el centro de la escena por la pugna entre el Estado y la Iglesia Católica en cuanto a los roles de los padres y las madres, y, por otro, la promoción de derechos de los hijos ilegítimos que el Estado llevaba adelante.
\end{abstract}

Palabras clave: cine negro; cine argentino; masculinidad; período clásico-industrial; estado.

\section{Tensions of fatherhood and masculinity in Argentine film noir (1946-1952)}

\begin{abstract}
I will analyze in El ángel desnudo (Carlos Hugo Christensen, 1946), El crimen de Oribe (Leopoldo Torres Ríos and Leopoldo Torre Nilsson, 1950), La bestia debe morir (Román Viñoly Barreto, 1952) and La encrucijada (Leopoldo Torres Ríos, 1952) a set of items that problematize fatherhood as a family bond through different plots related to film noir. Although family is a prevalent notion in plots of the films made before the beginning of industrial cinema in Argentina, I am going to inspect its reconfigurations in a genre of a social critical nature such as film noir; at the same time, I recognize its particular
\end{abstract}


connotation in regard to the disintegration of families and male and female identities. I will consider the way in which films are influenced by contemporary debates about the crisis of the traditional nuclear family-motivated by the struggle between the State and the Catholic Church regarding roles of fathers and mothers-and, at the same time, by the promotion of the rights of illegitimate children that the State carried out.

Keywords: film noir; Argentine cinema; masculinity; classic-industrial; state.

\section{Introducción}

Un conjunto de películas realizadas desde 1946 hasta 1952 abordan -con algunos de los códigos genéricos del film noir estadounidense- el tema de la paternidad en sus argumentos. En el presente artículo llevaremos a cabo el análisis de cuatro de esos films para observar la manera en que son representadas en la pantalla una serie de problemáticas relacionadas con este aspecto de la vida familiar y social. La paternidad encarna valores institucionales que se manifiestan como ideales culturales y sociales, y en aquellas sociedades donde la familia nuclear es el modelo establecido se convierte en uno de los elementos primordiales de la constitución de la masculinidad.

Vamos a observar la manera en que Elángel desnudo (Carlos Hugo Christensen, 1946), El crimen de Oribe (Leopoldo Torre Nilsson y Leopoldo Torres Ríos, 1950), La encrucijada (Leopoldo Torres Ríos, 1952) y La bestia debe morir (Román Viñoly Barreto, 1952) dan cuenta o no de las pugnas que en ese entonces estaban teniendo lugar en el terreno socio-político y cultural acerca del rol paterno. Los protagonistas de estas películas se vinculan -de diversas maneras- con la paternidad, protegiendo a sus hijos o vengando la muerte de alguno de ellos. En los argumentos de estas películas se problematiza esta noción, y se abordan posibles interpretaciones acerca del significado de la paternidad a mediados del siglo XX en Argentina.

Para poder llevar a cabo este análisis es útil considerar los discursos predominantes en ese determinado espacio y momento de la historia. En ese sentido, nos resulta fundamental el aporte de Howard Becker (2015: 24):

La tarea de representar a la sociedad a menudo supone una comunidad interpretativa, una organización conformada por personas que acostumbran realizar representaciones estandarizadas de determinado tipo ("productores") para otras ("usuarios"), que a su vez suelen emplearlas para determinados propósitos estandarizados. Tanto los productores como los usuarios adaptaron su actividad a la actividad del resto, de manera tal que la organización de hacer y usar resulte, al menos durante determinado período, una unidad estable, un mundo.

De acuerdo con Becker, los productores, por un lado, llevan a cabo tareas de selección, traducción y organización de los elementos de la realidad con los que componen sus obras, y por el otro, los usuarios realizan tareas relacionadas con el uso de aquellas representaciones. Si bien los productores pertenecientes a una comunidad organizacional deciden qué elementos utilizar para la realización de las obras que componen, los usuarios son quienes en primera instancia elaboran un "constructo" a través del cual comprenden el sentido de las representaciones que contemplan; y posteriormente, se configuran en una "comunidad interpretativa", que entiende los códigos y normas del cine industrial.

De ese modo, la labor que realizan los usuarios con las obras completa la obra original: "El trabajo de producción de representaciones se divide entre los productores y los usuarios. El trabajo de los productores está allí, a disposición de los usuarios. Los usuarios tendrán que hacer eso que los productores no hicieron" (Ibíd.: 89). 
Entre los modos de uso e interpretación de las obras, uno privilegiado es aquel que busca en la obra el reflejo del mundo histórico y sus agentes sociales. En el caso del cine comercial "a los usuarios que esperan encontrar verdades sociales, y no sólo una película entretenida, tal vez les preocupe que el cineasta sacrifique la verdad, como sea que la definan, en favor de los estándares del oficio" (Ibíd.: 146). Siguiendo estos planteamientos, entendemos que la obra debe ser considerada en su representación de una sociedad que no conocemos y su diálogo con ella.

Así, las películas que analizaremos incluyen discursos sobre la paternidad que difieren de manera notable. Se pueden advertir, asimismo, diferentes valoraciones morales vinculadas con esas diferentes representaciones de la paternidad. No adoptaremos una postura que refleje de manera sumatoria la diversidad de expresiones acerca de la paternidad; pues consideramos que cada uno de esos discursos presenta una cierta verdad respecto de esta relación; consideraremos, entonces, la multiplicidad de visiones (en algunos casos contrarias) acerca de ese vínculo social y familiar y sus diferentes representaciones.

\section{Motivos paternales en el cine industrial argentino}

\section{a. El ángel desnudo o la desprotección paternal como contracara de la mas- culinidad tradicional}

Desde los primeros años del cine industrial argentino, el melodrama se constituyó como la matriz narrativa a partir de la cual los relatos se organizaron y presentaron una imagen de Argentina basada en una visión de la cultura local "respetable, segura y sana" (Karush, 2013: 171). Como manifiesta Ricardo Manetti, el orden familiar patriarcal es el eje moral y social a través del cual las historias del melodrama encuentran su cauce: "el género responde a un modelo patriarcal donde la figura del padre -en términos simbólicos, padre-familia, padre-Dios, y padre-Estado-constituye la base fundante de una ley que no debe ser transgredida" (Manetti, 2000: 194). En Argentina, los códigos y elementos del cine negro ingresan a la industria, a la vez que ésta usa para sus relatos parámetros de la matriz melodramática. El ángel desnudo no es la primera película que introduce elementos noirs en el cine argentino; en su argumento prevalecen, además, rasgos tanto del melodrama como de la narrativa gótica. A la vez, este film retoma un elemento sintáctico del melodrama popular argentino, aquel referido al "mal paso" dado por la joven protagonista. El elemento de la transgresión femenina se convertiría eventualmente en el origen de una variante de melodrama particular de la cinematografía nacional, influida en gran medida por las letras de tango, en que prevalece el melodrama de madre. En esta variante del género, la madre se convierte en paliativo de todos los errores y culpas del hijo, y el éxito de éste es presentado en paralelo al hundimiento de la madre. El peso de la culpa recae en última instancia sobre ella, y el hijo reconoce al final de su travesía el sacrificio que su madre había realizado. Esta variante no está exenta de críticas a los rasgos patriarcales del género:

Cierta objeción de la crítica feminista consiste en haber establecido que el cine, en su tradicional modelo patriarcal, siempre tuvo una mirada esencialista, extrema, sobre la mujer: madre o puta, sin términos medios. [...] "Los hombres son quienes han definido las cosas visibles del cine [...]. En el marco de referencia de este cine, las teorías narrativas y visuales masculinas son las que construyen el espacio de la mujer como ámbito para ser mirado" (Ibíd.: 210). 
En una inversión de esta lógica pareciera incurrir El ángel desnudo, ${ }^{2}$ una película sobre una adolescente que no quiere formar parte de las mujeres formadas para ser miradas, pero un error del padre la lleva a ceder ante los avances de una figura masculina aterradora y perversa.

La película, estrenada el 14 de noviembre de 1946, forma parte de un núcleo de obras trascendentales en la filmografía de Christensen, y fue motivo de censura estatal, "prohibida para menores de 18 años por tener un plano medio de Olga Zubarry mostrando su espalda desnuda" (Kelly-Hopfenblatt y Trombetta, 2009: 260). La primera etapa de la obra de Christensen se caracteriza por un "pre-Lolitismo, probablemente reflejando y recreando una suerte de imaginario sensual de los 40s, también su imaginación maduró en seguida para incursionar en la sensualidad adulta" (Ruffinelli, 1998: 287). Las subsecuentes películas de Christensen se enfocarían en los tópicos de la pasión y la obsesión. Así es que surgen obras como Safo (1943), El ángel desnudo (1946) y Los pulpos (1948). Más adelante en su filmografía, Christensen ingresaría de lleno en la elaboración de películas de cine negro, al realizar La trampa (1949), No abras nunca esa puerta y Si muero antes de despertar (las dos de 1952) -la primera, adaptación de la novela Algo horrible en la leñera de Anthony Gilbert, y las dos siguientes versiones de relatos de William Irish, escritor que sirvió de fuente de relatos para muchas películas de cine negro de Hollywood-. ${ }^{3}$ Sin embargo, como sugieren George y Meneses,

El ángel desnudo, en el clásico molde noir, teje una red de engaño y abuso, atrapando a una víctima adolescente en sus múltiples hilos: el jugador compulsivo, sus habilitadores y sus torturadores, así como el acosador demoníaco y el posible violador. El destino de Elsa está sellado desde el principio. No hay salvación en este cuento pesimista, ni consuelo en su resurrección en forma de ángel desnudo (George y Meneses, 2018: 61).

Al inicio del film, luego de cometer un crimen, la policía arresta al protagonista Gaspar Las Heras-. Después comienza un flashback que conducirá al asesinato de Lagos Renard por parte de Gaspar, para vengar la muerte de su hija. A diferencia de las mujeres de los melodramas de madre de las décadas del 30 y 40, el peso de la culpa no recae en su hija sino en Gaspar, quien debe hacerse cargo de reparar el daño causado por años de malgastar el dinero y consentir a su única hija con grandes gastos, incluso si ella no demuestra intereses materiales, sino contrariamente, su preferencia por el genuino afecto de quienes la rodean. Gaspar vive en un hogar en el cual las mujeres lo superan en número (su hija Elsa y su hermana Diana) y donde es notable la ausencia de la madre de Elsa, quizás fallecida. Su hermana, Diana, reprocha constantemente a Gaspar por no cuidar su dinero. Gaspar presenta un lado oscuro al no poder controlar sus vicios. Esto lo lleva a perder el dinero de su empresa, y al consecuente pedido de ayuda a su hija. Este ruego por auxilio termina con el sacrificio de la hija (al contrario de lo que sucede en el melodrama de madre) e implica, por parte de Elsa, la toma de conciencia de la dualidad de las figuras masculinas: por un lado, su padre, cariñoso y respetuoso de las mujeres de su familia, pero fracasado en lo económico por una fuerte debilidad espiritual, representada por el vicio del juego; por otro, Lagos Renard, quien configura un tipo de masculinidad opuesta a la de Gaspar. Definen a este personaje su individualidad, su obstinación, su obsesión con la belleza femenina y la falta de escrúpulos.

El frágil espíritu de Gaspar se acerca al personaje clásico del film noir: el hombre débil que se deja llevar por la belleza de una mujer y termina en la ruina (como sucede en Double Indemnity, 1944; Scarlett Street, 1945; Laura, 1944; etc.). En este caso en particular,

2 Basada libremente en la novela corta La señorita Else (1924) de Arthur Schnitzler.

3 Phantom Lady (R. Siodmak, 1944), The Window (Ted Tetzlaff, 1949), La ventana indiscreta (Alfred Hitchcock, 1954). 
el desequilibrio generado por la necesidad de consentir a su hija y su hermana, como si esto subsanara su falla en cuanto a lo económico, derivó en la muerte de su hija y su posterior arresto. Sin embargo, existe una diferencia fundamental respecto de la tradición del film noir y la caída del hombre: la femme fatale no está dentro del repertorio de personajes. En cambio, la figura femenina que lo lleva a la desgracia es su propia hija, quien sufre una tragedia a causa de la pérdida de su inocencia desencadenada por el vicio del juego de su padre. Por otra parte, el personaje de Lagos Renard recuerda en gran medida al villano de la literatura gótica, que captura a la joven inocente y no le permite escapar de su morada. De este modo, pone en peligro la virtud y la inocencia. Como un clásico villano del gótico, su principal poderío radica en la palabra, en sus virtudes de orador. Al mismo tiempo, este personaje es la contrapartida del afecto paternal, en tanto presenta el lado más oscuro de la adultez masculina y el dominio total sobre la mujer, cuyo deseo se sacrifica por completo, víctima de las fantasías del hombre.

Al colocar el deseo masculino en el centro de la trama, El ángel desnudo expone los peligros de la desprotección paternal o más aún la potestad del padre de sacrificar a su hija, un motivo que puede retrotraerse al menos hasta la Virginia romana y en cierta medida hasta el sacrificio de Ifigenia. En una trama pautada por el vicio, el juego encarnado por Gaspar lo lleva a dar el primer paso hacia su destrucción; y el camino culmina con el deseo sexual desenfrenado de Lagos Renard. De este modo, Gaspar presenta una versión no hegemónica de la paternidad como valor primordial de la dominación masculina, en el modo en que la entiende Pierre Bourdieu (2000: 35):

Si la relación sexual aparece como una relación social de dominación es porque se constituye a través del principio de división fundamental entre lo masculino, activo, y lo femenino, pasivo, y ese principio crea, organiza, expresa y dirige el deseo, el deseo masculino como deseo de posesión, como dominación erótica, y el deseo femenino como deseo de la dominación masculina.

Lagos Renard ejerce este tipo de dominación con Elsa; antepone su deseo masculino frente al de ella. Sus actos demuestran de manera evidente las operaciones de dominación masculina tradicionales, a partir del acoso, la violencia y el forzamiento, que terminan por imponerse frente a la voluntad de Elsa, impotente y reducida por completo a la pasividad. De todos modos, el film pone en juego la idea de la defensa del honor de la hija por parte del padre. Esto puede ser visto, dentro de la lógica del film, como un último intento de Gaspar por recuperar la "masculinidad perdida" al haber desperdiciado todo su dinero y arruinado la vida de su hija. Bourdieu señala que hay ciertas tareas que implican la demostración de una característica especial del hombre, en contraste con acciones que presuntamente deben llevar a cabo las mujeres: "Esta inversión primordial en los juegos sociales (illusio), que hace el hombre que es hombre de verdad: sentido del honor, virilidad, manliness" (Ibíd.: 65). En este sentido, el honor es una sumisión a la norma por parte del hombre que parece no encontrar alternativa al verse reducido a todo lo que implica la negación de la masculinidad:

Un hábito construido de acuerdo con la división fundamental [...] en suma, de lo masculino y de lo femenino, y un espacio social organizado también de acuerdo con esta división que engendra, como tantos dictadores, las inversiones agonísticas de los hombres y de las virtudes, todas ellas de abstención y de abstinencia, de las mujeres (Ibíd.: 66).

Gaspar enfrenta a Lagos Renard para recuperar su honor, pero pierde su libertad y acaba desperdiciando todo: su hija, su trabajo, su honor como miembro destacado de la sociedad. Por otro lado, Lagos Renard, quien se erige como aquel que ejerce la dominación plena de la mujer, es la cara siniestra y perturbadora de la masculinidad y también encuentra un final desgraciado. 


\section{b. La puesta en marcha de nuevas masculinidades en $E l$ crimen de Oribe}

En El crimen de Oribe (1950), hay una representación de la paternidad con características distintas a las descritas en el apartado anterior. El film, adaptación de la novela corta El perjurio de la nieve (1944), de Adolfo Bioy Casares, relata el viaje de Villafañe, un periodista de Buenos Aires que se dirige hacia el sur y debe detenerse en un pueblo entre las montañas luego de perderse en el camino a su destino. En ese lugar, conoce a las hijas de Vermehren, se enamora de una de ellas y le causa la muerte de una manera muy peculiar.

La película sería la primera obra como realizador de Leopoldo Torre Nilsson, aunque en los créditos figure junto con su padre, Leopoldo Torres Ríos, quien tuvo poca incidencia en la realización: "la integración de su nombre en los créditos fue sobre todo una estrategia para que su hijo tuviera absoluta libertad, porque la reputación de Torres Ríos impedía todo rechazo posible de los productores" (Hausmann, 2017: 111-112). Torre Nilsson también escribe el guion de la película, una adaptación del relato original de Bioy Casares, que aborda la temática del encierro -"una de las características determinantes de la narrativa temprana de Bioy" (Setton, 2010: 66)- a través de una trama deductiva que posibilita una lectura en clave policial. La filmografía de Torre Nilsson sería afín a los tópicos que Bioy incluía en sus obras: "el aislamiento, el encierro y, especialmente, el carácter opresivo y siniestro de los vínculos familiares y domésticos que rigen la vida cotidiana se muestran como recurrencias insoslayables en su obra" (Ibíd.: 68). Además, la primera obra de este director ya anunciaba la voluntad de "desajustar las normas genéricas tradicionales e introducirse en los quiebres que hostigan la tranquilidad del receptor" (España, 1998: 59). Si bien el texto original contiene rasgos genéricos que permiten asociarlo con el policial en su variante de enigma con elementos fantásticos, donde el misterio de la muerte de Lucía Vermehren debe ser resuelto, la película se acerca a la categoría de film noir. Esto se debe a la

ambivalencia de los caracteres, junto con la ambigüedad de las víctimas "siempre semisospechosas", así como las contradicciones en la figura del héroe [...] La perspectiva respecto del crimen y la muerte excluye el punto de vista de la ley, en oposición al documental policial, que los narra desde una perspectiva externa y oficial (Setton, 2010: 73). ${ }^{4}$

A partir de los personajes masculinos, es posible considerar una especie de división fundamental entre dos generaciones que pugnan por el verdadero valor de las relaciones afectivas. Por un lado, Vermehren compone una figura paternal sobreprotectora que promueve el encierro en su territorio hogareño; por el otro, las figuras más juveniles (pero ya adultas) de Villafañe y Oribe, uno periodista, encargado de interpretar el mundo que lo rodea y comunicarlo a sus pares; y el otro, poeta, amante de los misterios y cautivado por los sucesos casi fantásticos que lo rodean.

En ese sentido, Vermehren pareciera condensar las características de una paternidad tradicional. Sin embargo, este tipo de paternidad es puesta en tensión por la ausencia de madre en el hogar, y la exigencia que implica la enfermedad de su hija Lucía, a quien debe proporcionarle los cuidados asistenciales y hogareños, tradicionalmente a cargo de las mujeres. Por ello, Vermehren es una inversión de la figura paternal de la sociedad industrial. En este tipo de sociedades,

el mundo se divide en dos esferas heterogéneas que no se comunican: la privada, que es el hogar familiar regenteado por la madre; la pública y profesional, reino exclusivo de los hombres. [...] La sociedad industrial, al alejar al padre del hijo, 
ataca el poder patriarcal. Es el fin del patriarca todopoderoso que impone la ley a su esposa y a sus hijos (Badinter, 1993: 111-112).

De este modo, Vermehren se instaura a sí mismo como un último enclave de la paternidad tradicional y represiva en un mundo de cambios. La pulsión por repetir el mismo día indefinidamente acentúa aún más la urgencia de este personaje por mantener las formas tradicionales, a través de las cuales considera que salvará a sus hijas.

Las acciones de Oribe y Villafañe que franquean el terreno de Vermehren pueden ser entendidas como el pasaje de hombres jóvenes a través de los ritos de iniciación en la masculinidad. Estos ritos "siguen existiendo en numerosas sociedades humanas y se practican con mayor o menor crueldad y dramatización" (Ibíd.: 96). Las tres etapas de las que consta el rito de iniciación son "la separación de la madre y del mundo femenino; la transferencia a un mundo desconocido; y el sometimiento a unas pruebas dramáticas y públicas" (Ibíd.: 94). De esa manera, Villafañe ingresa en soledad a un mundo desconocido, rodeado de otros hombres en un antiguo hotel en el medio de un pueblo lejano de la Patagonia. Al mismo tiempo, Oribe se encuentra en el punto intermedio de su pasaje por su iniciación masculina, con mayor conocimiento del entorno. Oribe y Villafañe, ya alejados de sus madres y separados del mundo femenino, emprenden su resocialización con el resto de los hombres que forman parte de la adultez, pero no llevan a cabo sus hazañas de la misma manera que los demás. Si bien el desapego de las figuras femeninas no es visible, sí es posible vislumbrar cómo Villafañe es arrancado muy drásticamente de un espacio seguro, de contención, y lanzado a otro donde se le exige que ponga a prueba su instinto de supervivencia.

En este nuevo terreno, cobra importancia la figura de Oribe, y mientras avanza el film Villafañe encontrará en él la demostración de una alternativa para sus días en el alejado pueblo patagónico. De algún modo, el aprendizaje de un par de su mismo sexo lo insta a traspasar las puertas de la casa de Vermehren, con el objetivo no sólo de resolver el misterio del encierro de las hijas en la casa, sino también para relacionarse con Lucía y, de este modo, poner fin a una paternidad cruel y castradora. Como menciona Oribe, el ingreso furtivo en la casa terminó con el infierno del que eran víctimas las jóvenes.

El ejercicio del dominio y la violencia diferencian a Vermehren de Oribe y Villafañe. El padre de las jóvenes representa una masculinidad que apela al ideal de hombre duro. Por otra parte, este hombre enfermo y fragmentado desempeña funciones ambiguas respecto de los roles de género: por un lado, es el organizador de la vida doméstica y la economía hogareña (labores atribuidas tradicionalmente a la mujer) y, por otro, desempeña el papel de protector y proveedor de recursos. Ante la enfermedad de Lucía, se encuentra en la disyuntiva de dejar morir a su hija o desarrollar una vida en la cual el encierro es la ley. En esta lógica del encierro, la aparición de nuevos hombres no supone solamente la intimidación de una intrusión a la propiedad privada y la eventual muerte de Lucía, sino que también implica la amenaza del ingreso de una nueva masculinidad. La violencia de Vermehren es representativa de una dualidad sobre la cual se exponen dos modos de mutilación: "mutilación de su feminidad o mutilación de su virilidad; herida mortal para su «alma femenina» o bien ahogamiento en el regazo maternal" (Ibíd.: 156).

El crimen de Oribe parece sugerir una posible evolución en las representaciones de la masculinidad en el cine argentino a partir de la confrontación entre dos hombres que se complementan y no temen considerar al otro como un aliado, contra un hombre individual, arcaico y violento que encarna la visión tradicional y protectora, pero a la vez mutilada y enfermiza de la masculinidad. El hombre del futuro no puede contar consigo mismo para resolver sus problemas, sino que debe complementarse con 
otros que puedan atender a aquellos aspectos que lo conformarían en su plenitud. No obstante, el esfuerzo común de Oribe y Villafañe acaba con la vida de uno de ellos y deja al otro en soledad, en el medio de una ciudad colmada por otros hombres. La aventura de Villafañe resultó ser un atisbo de un posible mañana en el cual los hombres colaboren entre ellos, cada uno aportando con su capacidad para derrumbar las paredes de la prisión de la familia tradicional.

\section{c. El Estado como tutor y promotor de justicia social en La encrucijada}

La encrucijada (1952) arroja otra luz sobre la función protectora del padre: un delincuente decide huir de la cárcel para salvar a su hijo de un destino similar.

Esta película de Leopoldo Torres Ríos puede incluirse en una serie de obras que abordan lo carcelario desde finales de los años cuarenta y durante inicios de los cincuenta. Además de esta obra se pueden mencionar Apenas un delincuente (1949) de Hugo Fregonese, Mujeres en sombra (1951) de Catrano Catrani, y Deshonra (1952) de Daniel Tinayre. Es destacable que las últimas dos, al igual que La encrucijada, ofrecen una mirada de la cárcel que se acerca a lo melodramático. Narran, así, las penurias en el interior de los presidios. En ese sentido, el cine carcelario argentino se presenta como una inflexión local sobre un tipo de representación de las prisiones que en la mayor parte del registro cinematográfico se adecua a las exigencias del género al que pertenezca cada obra. De ese modo,

la inflexión más importante que se produce en el cine argentino y latinoamericano, sin duda, es su tendencia a usar el melodrama para acercarse a la vida de los presos. Es que la narración melodramática resuelve imaginariamente la contradicción entre condena y atracción moral que suscita el delito en las sociedades latinoamericanas (Aguilar, 2007: 165).

Durante la mayor parte de su filmografía, Torres Ríos fue un director formado y desarrollado en la industria, a través de la producción en estudios. Sin embargo, esto no impidió su interés por elaborar películas que cuenten con un despliegue técnico y estético, como supo mostrar en La vuelta al nido (1938), que luego fue considerada por la crítica no sólo "una rareza, sino también un anticipo del tipo de cine que estaban por realizar los jóvenes directores de la generación del 60" (Peña, 2012: 70). Hacia la maduración de su carrera, que tuvo lugar desde finales de los cuarenta, puede advertirse el interés en buscar un cruce entre el lirismo y el realismo en films tales como Santos Vega vuelve (1947), El regreso (1950), la ya mencionada El crimen de Oribe, que se intercalan con obras que tienden a una "depuración expresiva, profundizando en ambientes y temas que trataba desde sus comienzos" (Peña, 2012: 112). Entre esos films puede encontrar su lugar La encrucijada, que utiliza recursos estéticos y narrativos -como los flashbacks y fotografía en alto contraste y clave baja- que trascienden el realismo y sugieren un universo expresivo con mayores matices.

En este film se hace presente una serie de elementos de relevancia para la figura paterna, que al mismo tiempo da cuenta de diversas problemáticas concurrentes en el momento de realización de la película. En primer lugar, es preciso referirse a la relación que se establece entre la pobreza y la delincuencia: el protagonista de la película, Selvi, no delinque por una ambición, sino que lo hace por falta de trabajo y necesidad de provisión de sus seres queridos. En ese sentido, la película asocia la delincuencia con la ausencia de justicia social. Selvi es presentado como una víctima de la marginalización social, y su posterior ingreso a la cárcel no sólo no lo salva, sino que además lo transforma en un hombre resentido. Éste es el segundo aspecto sobre el cual el film enfatiza su carga dramática: la cárcel como posibilidad de transformación de los sujetos que compondrán una nueva sociedad. De manera similar 
a lo que sucede en Deshonra de Daniel Tinayre del mismo año, la película aborda temáticamente la reforma del sistema penal que se estaba llevando a cabo, promovida por Roberto Pettinato:

entre 1946 y 1947 Roberto Pettinato impulsó una abigarrada lista de cambios en los penales argentinos. El discurso estatal sobre el castigo pasó de estar centrado en los derechos de la sociedad a girar en torno a los derechos del preso. La reforma peronista promovía el "desagravio histórico de los penados" e instalaba medidas democratizadoras de la sociedad carcelaria ya existente. [...] la reforma de Pettinato no se basaba solamente en la mejora de las condiciones de vida, sino que implicaba un cambio de estatus, tanto para el preso como para quienes administraban cotidianamente su pena en las prisiones. En función de ello, el preso se hacía visible en los medios masivos y se lo integraba a distintas prácticas sociales y políticas en actos simbólicos que se desarrollaban en la Penitenciaría Nacional. Con respecto al personal carcelario, se puso en marcha la concesión de mejores condiciones laborales así como una tarea de organización y jerarquización de sus cargos (Kriger, 2010: 183-184).

En ese sentido, La encrucijada parece sugerir la desmarginalización del protagonista al presentar la posible redención de un delincuente que había resignado cualquier posibilidad de estar en armonía con la sociedad. Las escenas en que se presenta la Penitenciaría Nacional luego de la reforma hacen uso de planos generales, y se ve a los presos realizar actividades al aire libre, sin llevar uniformes que los transformen en una masa homogénea. En relación con ello, el argumento del film es impulsado por un flashback que tiene lugar a causa de la inquietud de las autoridades de la cárcel, quienes veían en Selvi a un hombre reformado con poco tiempo de condena por delante. Un elemento de la puesta en escena que da cuenta de los beneficios de la reforma es el cambio en el rostro de Selvi: la cicatriz en su cara, producto de la violencia carcelaria, convirtió al protagonista en un delincuente con una marca social, que precisaba esconder para poder salir a la calle. Asimismo, hacia el final del film, con la eventual redención del personaje principal, podemos advertir la ausencia de esta marca. Esta última escena vuelve ejemplar la desaparición de esa herida en su rostro: ejemplo de redención y de renacimiento, tanto del individuo como de la sociedad, gracias a las reformas del gobierno peronista.

Al mismo tiempo que el film expone las penurias a las que eran sometidos los presos y las -en ese entonces- novedosas oportunidades que les ofrecía la reforma carcelaria, incluye elementos que sugieren la posible búsqueda de armonía entre los objetivos del peronismo y el dogma católico. En ese sentido debemos destacar el importante influjo político de la Iglesia católica en el país desde la década de 1930. Logró ocupar espacios y consolidó posiciones y reconocimientos en el campo político y social, aunque no haya alcanzado el proceso de catolización por completo de la sociedad, a pesar de haber acompañado los golpes de 1930 y 1943, en los que veía la oportunidad de una corporativización de la sociedad argentina. Con la llegada del peronismo al poder en 1946, varios sectores del clero consideraron que la Iglesia podría instrumentalizar al nuevo gobierno, darle contenidos. El clero no tardó en asociar el decaimiento de los índices demográficos de los integrantes de los hogares argentinos con una aparente crisis de la familia. No obstante, el sector eclesiástico no fue el único en prestar atención a estas problemáticas, sino que ciertas secciones gubernamentales siguieron una línea de políticas redistributivas que formaron parte de los objetivos de la "justicia social":

Incremento del salario familiar, disminución de impuestos a familias numerosas, fomento de subsidios y de préstamos por matrimonio y nacimientos, prioridad de empleo y acceso de vivienda a padres de familia. [...] muchas de estas políticas [...] 
se vinculaban estrechamente con un objetivo del gobierno: el crecimiento vegetativo de la población considerado la base del desarrollo económico (Bianchi, 1999: 120).

El peronismo, en este sentido, adhirió a una concepción de familia afín a las ideas de la Iglesia católica, lo que se vio reflejado de manera aún mayor en las declaraciones de los miembros de la Convención Constituyente de 1949. En este sentido, Raúl Mendé sostuvo que el ordenamiento cristiano de la familia era el "ordenamiento tradicional argentino".5

No obstante, existían desacuerdos entre el Estado y la Iglesia en cuanto al avance del primero en detrimento de la segunda hacia el interior de la familia. En particular, la Iglesia consideraba que ese avance contenía un carácter "hedonista", al sugerir que otorgaba excesivos privilegios a la familia. Los beneficios laborales y el acceso a mejores condiciones de vida en las grandes urbes eran entendidos por la Iglesia como afrentas contra el hogar familiar, y la ausencia de adultos en el hogar durante el día era vista como la ausencia del "piloto de la nave" (Ibíd.: 122-123).

Entre otras políticas, el reconocimiento de los hijos ilegítimos por parte del Estado estaba en la línea con la "implantación de un 'nuevo patriarcado' que reformuló la relación entre la familia y el Estado debilitando los derechos tradicionales de los hombres en favor de los niños y las mujeres" (Cosse, 2006: 15). Este mismo proceso ayudó a visibilizar la heterogeneidad de prácticas familiares en tensión con el establecimiento de un modelo de familia homogéneo y excluyente. Las leyes sobre legitimación de hijos naturales o provenientes del adulterio y el incesto apuntaron a otorgar dignidad a aquellos individuos que se encontraban en los márgenes de la sociedad al haber "sido engendrados por relaciones que contrariaban la institución matrimonial, el orden del parentesco legítimo y las bases normativas de la moral pública" (Ibíd.: 27).

En este marco, La encrucijada parece buscar enmendar los lazos entre el Estado y la Iglesia al presentar la redención de un personaje que -como se indica al inicio del film- es hijo "de padre desconocido". Su condición de hijo ilegítimo, asociada a las injusticias sociales que lo rodearon y afectaron durante su adultez, lo envió a los márgenes de la sociedad. En ese sentido, la cárcel funcionó, en primera instancia, como un espacio que profundizó la marginalización sufrida durante toda su vida. Posteriormente, la paternidad, junto a la reforma carcelaria, logró que Selvi pudiera reconstruirse como individuo en una sociedad que se encontraba preparada para forjar hombres del mañana. Su objetivo principal, entonces, se constituyó en la creación de una familia consumada tanto por la Iglesia, desde la unión matrimonial, y por el Estado, mediador y movilizador de reformas para el avance de la sociedad argentina. Es una paternidad moderna en la que las marcas sociales y culturales (expresadas por la cicatriz en el rostro de Selvi) pueden ser borradas a partir del esfuerzo de instituciones en conjunto, y a través de las cuales se pueden promover ideales de hombres nuevos que, en vez de delinquir, puedan ser privilegiados por los logros de un Estado participativo e impulsor de la justicia social.

\section{d. La bestia debe morir y el debate sobre la autonomía en la pedagogía infantil.}

Por último, otra visión acerca del paradigma de la paternidad es presentada en La bestia debe morir. ${ }^{6}$ La filmografía de Viñoly Barreto no ha sido suficientemente explorada. Este director uruguayo tuvo una formación universitaria en filosofía y teología, temas

\footnotetext{
5 Convención Nacional Constituyente. Diario de Sesiones. 24 de enero-16 de marzo. Buenos Aires, Congreso de la Nación. 1949, 392-394.

6 Adaptación de la novela de 1938 de Nicholas Blake, seudónimo de Cecil Day-Lewis.
} 
que se reflejan en sus películas, ${ }^{7}$ que exponen su interés en "las pasiones exacerbadas y era dueño de una cultura visual que le permitió crear algunas de las imágenes más intensas del cine argentino" (Peña, 2012: 127). En sus inicios en Argentina trabajó en la puesta en escena de obras teatrales (como La anunciación de Maria de Claudel) hasta iniciar - de la mano de Alberto de Zavalía- su carrera cinematográfica con Estrellita (1947). Luego de una serie de propuestas de géneros diferentes (que incluye Corrientes... Calle de ensueños! (1949), Con el sudor de tu frente (1950) y Reportaje en el infierno (1951)) consigue realizar La bestia debe morir en 1952, un film noir que tuvo buenas críticas en su momento, pero cuya mirada retrospectiva es aún más positiva, como da cuenta Fernando Martín Peña en 100 años de cine argentino y su proyección en festivales como Noir City en el cine SIFF de Seattle (Estados Unidos). ${ }^{8}$ Eduardo Russo, en uno de los pocos estudios que se han llevado a cabo sobre esta película, la liga a la herencia del thriller inglés, género del que directores como Alfred Hitchcock supieron sacar fruto: siguiendo a Todorov, considera que las películas de Christensen y Viñoly Barreto, basadas en obras de Nicholas Blake y Cornell Woolrich (bajo el seudónimo de William Irish) aluden "al tipo particular del relato de suspenso al que designa como la «historia del sospechoso-detective»" (Russo, 2005: 64)..$^{9}$ La acepción del thriller rescatada por Russo es categóricamente literaria, y en el análisis transpositivo que lleva adelante aplica los rasgos distintivos de ese género a obras cinematográficas: "El mundo del thriller es consustancial a una angustia estética que convoca a cierta dimensión fóbica del policial, y lo conecta con un terror sordo que el cine convirtió en una construcción privilegiada, aprovechando la habitabilidad propia del cine clásico" (Ibíd.: 65). Esta descripción del universo ficcional del género, al que según Russo corresponderían las películas, puede bien considerarse como una caracterización del mundo en que tienen lugar relatos de film noir. No obstante, reconoce en la filmografía de Christensen y Viñoly Barreto parte de la fuerza internacionalizada del cine negro hollywoodense, por el uso de una puesta en escena que pone de manifiesto recursos de esa categoría fílmica. En La bestia debe morir se puede descubrir "la corrosión de todo un imaginario patriarcal consagrado por la tradición del cine predominante argentino. [...] Lo que allí comienza es la historia de soledades absolutas, que la fatalidad convoca a la cercanía del crimen" (Ibíd.: 69).

Este film nos introduce en la historia de Frank Carter, un escritor que se encuentra envuelto en la historia del crimen de un rico terrateniente llamado Robert Rattery. El film presenta en su argumento algunos aspectos que se vinculan a la conformación de la masculinidad en la sociedad a partir de la presentación del personaje principal y su relación con otros hombres en el desarrollo del relato. En primer lugar, se elabora una dualidad en la manera en que afecta a Frank Carter la muerte de su hijo Marty. En ese sentido, la adopción de la identidad "Felix Lane" es configurada como una "máscara" de masculinidad que le sirve para vengarse del culpable de la muerte de Marty, Rattery. La composición de este personaje indica la posibilidad de que los hombres se transformen en monstruos sin piedad, y ése es el peligro que Frank reconoce al ver que Rattery es exitoso en cuanto a lo económico, social y con las mujeres: el villano del film es el paradigma del ideal masculino para la gran mayoría de los hombres:

Al promover esta imagen inaccesible de la virilidad se suscita una toma de conciencia dolorosa: la de ser un hombre inacabado. Para luchar contra ese sentimiento

7 El vampiro negro (1953), El dinero de Dios (1959) y Orden de matar (1965) dan clara cuenta de ello.

$8 \mathrm{El} 14$ de febrero de 2020 una restauración de la película realizada por la UCLA Film \& Television Archive fue proyectada en el cine SIFF Egyptian de Seattle en el marco de la muestra Noir City: https://www.siff.net/year-round-cinema/ film-festivals/noir-city/the-beast-must-die

9 "En este caso, un crimen se comete en las primeras páginas y las sospechas de la policía se dirigen a cierta persona (que es el protagonista). Para probar su inocencia, esta persona debe encontrar por ella misma al verdadero culpable, incluso si para ello arriesga, en tren de hacerlo, su propia vida. Puede decirse que en este caso el personaje es al mismo tiempo el detective, el culpable (a los ojos de la policía) y la víctima (potencial, de los verdaderos asesinos)" (Todorov, citado en Russo, 2005: 64). 
permanente de inseguridad, determinados hombres creen poder encontrar el remedio en la promoción de la hipervirilidad. De hecho, acaban siendo prisioneros de una masculinidad obsesionada y compulsiva que no les proporciona jamás la paz, sino que es fuente de autodestrucción y agresividad contra todos los que amenazan con poner fin a la mascarada (Badinter, 1993: 164).

Y en última instancia la hipervirilidad lleva a los dos hombres a su muerte: Frank Carter, actuando como Felix Lane, logra llevar a Rattery a un bote, donde éste demuestra su inseguridad, y expone en ese momento las máscaras que los resguardaban de la frágil ambigüedad y los temores que los llevaron a cometer actos criminales. Al destruirse la fachada, Frank Carter queda vacío y decide acabar con su vida, aunque a sabiendas de que pudo manifestar gracias a Ronnie, el hijastro de Rattery, su deseo educador de que el día de mañana no construya la máscara social de masculinidad tradicional.

En cierto modo, la tarea de Frank Carter es encarnar a Felix Lane en aras de acabar con la Ley del Padre. A través de esta ley-siguiendo las tesis lacanianas-, el padre otorga al hijo el poder de la primacía del falo, que le permite acceder a un nivel simbólico del lenguaje en el cual el falo se erige como representante de la única libido y por ende ratificadora del patriarcado: "El falo es el mayor significante, el significante de los significantes que rige los demás y permite la entrada del ser humano en el orden de la cultura" (Ibíd.: 167). La primacía del falo lleva a que el hombre considere que deba afirmar su masculinidad, y aquellos que fracasan en esa identificación recaen en un excesivo rechazo de la feminidad, que podría llevarlos a convertirse en violadores. Este tipo de violencia es representativa de un "modelo de hombre superviril, desmadrado y desfeminizado, [...] fuente de un verdadero malestar de identidad que causa una doble violencia: la que agrede a los demás y la que se vuelve contra sí mismo" (Ibíd.: 173). Rattery abusa de su posición de hombre e incurre en la violencia: acosa mujeres, golpea a niños, engaña a su esposa.

El ideal viril paga un alto precio, y eso es lo que sugiere la película a partir de las acciones y trayectos que llevan adelante el héroe y el villano, así como también por el modo en que se reflejan estas actitudes en los niños del film. Inicialmente Marty, y luego Ronnie, comienzan su incursión en el mundo de la adultez: el primero encuentra la muerte buscando la aprobación de los mayores, en especial de su padre; y Ronnie desarrolla un lado más rebelde al rechazar la influencia de Rattery y admirar la literatura de Felix Lane. Esto da lugar a una tensión en la manera en que se relaciona Frank Carter con el niño, debido a que mientras cree que debe proteger a Ronnie de las acciones violentas y represivas de su padrastro, reflexiona acerca de la posibilidad del desarrollo de su la autonomía.

La película pareciera dialogar entonces con las concepciones contemporáneas de la educación infantil. Durante dicho período, el peronismo elaboró una pedagogía en la que "los niños fueron interpelados como sujetos privilegiados por políticas sociales y moldeados por una pedagogía política progresivamente volcada hacia el adoctrinamiento y la búsqueda de inscripción de la niñez en las luchas por la hegemonía" (Carli, 2003: 259). El objetivo del peronismo en la promoción de ese tipo de políticas fue esbozar los rasgos -elaborando contenidos culturales y pedagógicos- de un tipo de hombre que el nuevo gobierno quería formar, hombres "inclinados profundamente al bien público e inspirados defensores de la verdad y del bien" (Perón, 1948). Dentro de los objetivos del primer Plan Quinquenal, un enunciado se refiere al "moldeamiento de la personalidad infantil", y en esa lógica tendrían lugar las ideas de Juan Cassani, pedagogo que consideró la educación como un "proceso espiritual" basado en la relación entre un joven y un adulto, quien se erige como discípulo del primero, para ponerlo "en contacto con el mundo de los valores" (Carli, 2003: 284). En ese sentido, 
el gobierno peronista insistió en la promoción de la justicia social en los niños y jóvenes, y a partir de 1949 Perón acentuaría los controles políticos sobre la lealtad al gobierno. En ese contexto, el Estado llegaba a los niños desde una transmisión de los adultos hacia ellos, una transmisión doctrinaria que suponía "un trabajo pedagógico que impactara en el orden de la subjetividad, es decir que impactara sobre la experiencia emocional y psicológica de los niños" (Ibíd.: 311). De esta manera, la apelación a la conquista del espíritu del niño se ligaba a los propósitos del segundo Plan Quinquenal, y se acentuaba aún más con la inclusión en las aulas, desde 1951, de textos político-doctrinarios tanto para docentes como para alumnos. A través de estas políticas, Perón consiguió que la Iglesia ya no fuera la que rigiera sobre el hogar, sino el Estado.

Frank Carter se preocupa por la educación espiritual de Marty, y luego de Ronnie, debatiéndose entre la duda acerca de si acompañar a los niños en sus aventuras, promoviendo la valentía de ellos, o controlarlos e imponerles límites acerca de hasta dónde es necesario que los futuros adultos arriesquen su vida para demostrar su coraje. Carter comprende que su tarea es influir en el espíritu de Ronnie, y no culpabilizarse por la muerte de Marty. Encarnar a Felix Lane significó para Carter la posibilidad de ponerse en el lugar de aquellos hombres que cumplen con la Ley del Padre y la siguen a rajatabla, para comprender que no era el camino adecuado a través del cual se pudiera incidir en los destinos de los más jóvenes. Asimismo, la particular relación entre Carter, Ronnie y Rattery presenta una tensión con la concepción de educación espiritual que el gobierno peronista llevaba adelante en ese momento. El film equipara a los adultos con los niños, con la convicción de que éstos son conscientes de sus acciones, y de que deben confiar en sus instintos, incluso si eso significa dejar fluir sus emociones.

En ese sentido, parece anticipar un tipo de paternidad que se promovería a través de los medios de comunicación masivos desde los inicios de la segunda mitad del siglo XX en Argentina. A través de revistas como Vea y Lea, publicaciones como Nuestros Hijos y columnas en algunos diarios de tirada masiva, un grupo de profesionales en psicología, ginecología y pediatría, influidos por los trabajos de Florencio Escardó, elaboraron textos, artículos y libros que impulsaban el desarrollo de un nuevo tipo de paternidad en Argentina que se adaptara a los cambios de la sociedad de la segunda mitad del siglo XX. En estos trabajos se promovía "el nuevo modelo paterno [que] se legitimó en su oposición a las imágenes de autoridad, a un escaso compromiso afectivo y a la distancia emocional en las relaciones paterno-filiales" (Cosse, 2009: 431). En este sentido, el nuevo modelo de paternidad tuvo su origen en relación con un nuevo paradigma de crianza de orden psicológico, y suponía un mayor compromiso de los padres con el cuidado y la atención afectiva de los hijos. Siguiendo ese precepto, pretendía que los roles ocupados por los padres fueran intercambiables, y para esto proponía la distribución de tareas relacionadas con los cuidados maternos en pos de fomentar un lazo afectivo basado en el cariño y la amistad:

Las nuevas disposiciones de la paternidad estaban recubiertas de una connotación de ruptura con el tipo de relaciones paterno-filiales que supuestamente había predominado en el pasado, en las cuales las bases de la autoridad del padre estaban asociadas al temor y a un poder desmedido. Por el contrario, en el horizonte de entonces la autoridad del padre debía ser el resultado natural del cariño, la confianza y el respeto (Ibíd.: 439).

De esta manera, al mismo tiempo que propone una alternativa dentro de la educación espiritual de los jóvenes, rechazando las paternidades en las que la autoridad era desarrollada a partir de la amenaza y la violencia, La bestia debe morir anticipa un tipo de paternidad que tiene en cuenta la autonomía de los niños, considerando 
como una pieza importante el acompañamiento desde una transmisión horizontal de valores, a diferencia de la transmisión vertical propuesta por las políticas pedagógicas estatales de entonces. Cuando Frank Carter consigue vencer a la figura que encarna las paternidades tradicionales, ya pudo plantar la semilla en el joven Ronnie, quien deja fluir sus sentimientos a través de un llanto, que, a la vez que expresa su tristeza, marca un final en su etapa de niñez y lo muestra preparado para su adolescencia y su vida adulta.

\section{Conclusiones}

A partir del análisis de estas cuatro películas podemos afirmar que existen diversos modelos paternales que no coinciden en los valores que promueven: estos van desde perspectivas negativas de las paternidades tradicionales hasta la construcción de paradigmas nuevos que van de la mano de políticas estatales y difusión en medios de comunicación. De la misma manera que en Argentina, en Hollywood, "el thriller duro noir revela una obsesión particular con la representación de desafíos y problemas dentro del ordenamiento de la identidad masculina y la autoridad cultural masculina" (Krutnik, 1991: 25). ${ }^{10}$ Sin embargo, la manera a través de la cual la industria estadounidense abordó la problemática fue a partir de la ubicación central de la mujer como objeto sexualizado, la femme fatale que define al edípico protagonista masculino. $\mathrm{Al}$ mismo tiempo, el ciclo de películas que inició el período clásico del cine negro presentó en la pantalla problemáticas ligadas a la nueva vida en la posguerra occidental. En sí, "estos thrillers de la década de 1940 ofrecen una serie de representaciones alternativas o 'transgresoras' del deseo y la identidad masculinas, junto con un encuadre manifiestamente más escéptico de la red de la autoridad cultural masculina" (Ibíd.: 88).

De manera análoga, las películas que hemos analizado dentro de la filmografía argentina exhiben cierto escepticismo en cuanto a la primacía del patriarcado y parecen sugerir una posible alternativa de escape, que consolide las posiciones de cada uno de los integrantes de la familia, a través de la construcción de personajes que se encuentran en situaciones adversas, que los separan del resto de sus familiares.

En primer lugar, El ángel desnudo pone en relieve los peligros del descuido de los hijos al lanzar al peligro de un adulto perverso a una inocente joven de 16 años. La película sugiere, a través del pasaje de Elsa, la hija de un empresario despilfarrador y negligente, que los padres deben prestar continua atención a sus hijos, como una manera de hacer perdurar el honor paternal. Por otro lado, Lagos Renard, el villano, exhibe todos los rasgos de una masculinidad violenta e imponente, que supone riesgos para la inocencia de los hijos. En definitiva, la película toma el lugar de Elsa para exponer una eventual rebelión ante un orden patriarcal que se olvida de sus intereses y sus deseos, y que se impone sobre ella como una red de la cual no hay escape.

Elcrimen de Oribe, como contrapartida, muestra los peligros de una paternidad que, en ese caso, sobreprotege a su descendencia y muestra los efectos de esa sobreprotección sobre sus hijas. La necesidad de continuar perpetuando el día previo a la muerte de una de ellas sugiere la insistencia de hacer resistir la organización familiar tradicional frente a un mundo en plena transformación. Como emblemas de esa transformación se erigen Oribe y Villafañe, dos jóvenes hombres que se complementan, con el fin de acabar con la tiranía de Vermehren, el padre de las jóvenes encerradas en su casa. La presentación de estos personajes sugiere la aparición en la sociedad de hombres que deben superar obstáculos para convertirse en hombres del mañana, representantes 
de una masculinidad moderna que trabaje en conjunto. Estos nuevos hombres, por otra parte, introducen una nueva instanciación de la sexualidad, que, por un lado, contrasta con el carácter reproductivo que lleva inscripto el padre de las jóvenes en el propio nombre (sich vermehren: multiplicarse, reproducirse); por otro, la marcada sugerencia del vínculo homoerótico entre Villafañe y Oribe (presente en el relato de Bioy y todavía más subrayado en esta adaptación fílmica), que también contrasta con los modos tradicionales de la masculinidad sostenidos por la Ley del Padre.

Cabe destacar que en estas primeras dos películas las figuras paternas parecieran comprender la perdición de sus hijas no solo como un fracaso en cuanto a su rol como padres, sino como el final de su labor masculina en el mundo que habitan: la pérdida de una hija en la viudez es casi una concreción de aquella iniciada con la muerte de sus esposas. La muerte de sus hijas, extensiones de sus esposas (esto es claramente expresado en El ángel desnudo, donde un cuadro de la madre de Elsa muestra el sorprendente parecido con la joven), representa un fracaso existencial de magnitudes insondables.

Por otro lado, La encrucijada presenta los modos en los que la familia, el Estado y la Iglesia pueden trabajar en conjunto para reformar a un hombre y recomponer el hogar en un contexto de injusticia social. La historia de Selvi ejemplifica el paso de un sujeto marginalizado -que fue despreciado por las instituciones carcelarias, "marcado" por su pasado como delincuente, alienado por su condición de pobre y "de padre desconocido"-que, urgido por la posibilidad de que su hijo encuentre un destino igual al suyo en el crimen, huye de la cárcel que -en plena reforma peronistalo contenía y buscaba reincorporarlo a la sociedad, para poder salvar el futuro de su hogar. Finalmente, la tríada Estado-Iglesia-Familia se consagra como salvadora del personaje principal y su hogar. De ese modo, esta película sugiere que una paternidad que se encarame dentro de los patrones de la justicia social no puede existir sin tutela estatal de la familia y acompañamiento de la Iglesia.

Finalmente, el caso de La bestia debe morir expone la necesidad de educar a los jóvenes en el terreno espiritual, al rechazar algunas concepciones de la política pedagógica contemporánea a su producción, manifestando la posibilidad de que una educación infantil pueda llevarse a cabo mediante la aceptación de la autonomía de los niños, en la cual los padres deben funcionar como una guía que incentive a los más jóvenes a seguir sus instintos y defender su anhelo de aventurarse ante lo desconocido. La máscara de masculinidad que el protagonista decide colocarse para enfrentar a Rattery ratifica el rechazo por un tipo de dominación masculina que se apoya en la Ley del Padre para sostenerse en el tiempo e imponerse sobre aquellos considerados inferiores. La paternidad que expone esta película anticipa un modelo que en décadas siguientes sobrevendrá sobre la cultura y los medios de comunicación en Argentina.

Con el análisis de estas películas no pretendemos dar cuenta de representaciones que funcionen como reflejo del Zeitgeist contemporáneo; para efectuar un análisis de esa índole deberíamos tener en cuenta el contexto en un sentido más amplio, considerando también las películas más exitosas y comentadas en la esfera pública. Sin embargo,

aquellas películas que inicialmente parecen ofrecer pocas perspectivas para recompensar el análisis crítico, sobre la base de sus cualidades textuales intrínsecas, pueden revelar mucho sobre su momento histórico cuando son consideradas dentro de su contexto cultural más amplio (Chopra-Gant, 2006: 7). 
La intención de este trabajo ha sido presentar una multiplicidad de visiones alternativas de la paternidad que generan tensiones acerca de los roles paternos en función de su carácter primordial como consolidador de una masculinidad tradicional. Asimismo, es posible trazar un camino que comienza presentando una paternidad cuestionable, continuada por una alternativa en la juventud, y bifurcándose en dos posibilidades: la conciliación de la familia tradicional con las instituciones autoritarias o el reconocimiento de la autonomía de los niños. De tal manera, los films hacen posible atisbar una transición que tiene lugar desde mediados de la década del cuarenta hasta inicios de los cincuenta en la que los roles paternos fueron objeto de diversas miradas que convergieron a través de ese período. En ese sentido, las primeras películas hacían hincapié en una protección paternal en el espacio hogareño, pero se cuestionaban acerca del grado adecuado de la misma; en contraposición, las últimas obras dan cuenta de la relevancia de la presencia paterna en la crianza del hijo, para -en primer lugar-garantizar una vida en sociedad más justa, al armonizar la vivencia hogareña con las instituciones eclesiástica y estatal, y-en segundo término- procurar una masculinidad que no atente contra la sociedad y el futuro de las próximas generaciones. Hasta qué punto el Estado tuvo que ver con la representación de estas concepciones escapa a los objetivos de este trabajo, pero cabe subrayar que los debates acerca de la paternidad y la masculinidad que siguieron adelante en la cinematografía argentina desde finales de los cincuenta y durante la década siguiente eclosionaron con la aparición de los jóvenes y sus preocupaciones en los films de la Generación del 60. 


\section{Q Bibliografía}

»Aguilar, G. (2007). “Culpable es el destino: el melodrama y la prisión en las películas Deshonra y Carandiru”. Nueva Sociedad, 208, 162-178.

" Badinter, E. (1993). XY. La identidad masculina. Madrid: Alianza Editorial.

» Becker, H. (2015). Para hablar de la sociedad. La sociología no basta. Buenos Aires: Siglo XXI.

» Bianchi, S. (1999). “Catolicismo y peronismo. La familia entre la religión y la política (1945-1955)". Boletín del Instituto de Historia Argentina y Americana “Dr. Emilio Ravignani, 19, 115-137.

»Borde, R. y Chaumeton, E. (1958). Panorama del cine negro. Traducción: Carmen Bonasso. Buenos Aires: Losange.

》Bourdieu, P. (2000). La dominación masculina. Barcelona: Anagrama.

"Carli, S. (2003). Niñez, pedagogía y política. Transformaciones de los discursos acerca de la infancia en la historia de la educación argentina entre 1880 y 1955. Buenos Aires: Miño y Dávila.

»Chopra-Gant, M. (2006). Hollywood Genres and Postwar America: Masculinity, Family and Nation in Popular Movies and Film Noir. Londres: I.B. Tauris.

»Cosse, I. (2006). Estigmas de nacimiento: Peronismo y orden familiar 1946-1955. Buenos Aires: Fondo de Cultura Económica.

»Cosse, I. (2009). "La emergencia de un nuevo modelo de paternidad en Argentina (1950-1975)”. Estudios demográficos y urbanos, 71, 429-462.

»Christensen, C. H. (1946) El ángel desnudo (film).

»De Lauretis, T. (1992). Alicia ya no: Feminismo, Semiótica, Cine. Madrid: Ediciones Cátedra.

»España, C. (1998). “Emergencia y tensiones en el cine argentino de los años cincuenta". Nuevo texto crítico, 21/22, 45-73.

»George, D. y Meneses, G. (2018). Argentine Cinema. From Noir to Neo-Noir. Londres: Lexington Books.

» Hausmann, M. (2007). “Una investigación fílmica en un laberinto literario. El crimen de Oribe de Leopoldo Torre Nilsson (1950)". Romanische Studien, 6, 107-122.

» Karush, M. (2013). Cultura de clase. Radio y cine en la creación de una Argentina dividida (1920-1946). Buenos Aires: Ariel.

» Kelly Hopfenblatt, A. y Trombetta, J. (2009). “Características de la censura entre 1933 y 1956. Continuidades y rupturas en la identidad nacional”. En: Lusnich, A. L. y Piedras, P. (eds.), Una historia del cine político y social en Argentina, vol. I. Buenos Aires: Nueva Librería, 25-41.

»Kriger, C. (2010). Cine y peronismo. El Estado en escena. Buenos Aires: Siglo XXI.

» Krutnik, F. (1991). In a Lonely Street. Film Noir, Genre, Masculinity. Londres: Routledge.

"Manetti, R. (2000). “El melodrama, fuente de relatos. Un espacio artístico para madres, prostitutas y nocherniegos melancólicos”. En: España, C. (dir.), Cine 
argentino: Industria y clasicismo, 1933-1956, vol II. Buenos Aires: Fondo Nacional de las Artes, 188-269.

»Peña, F. M. (2012). Cien años de cine argentino. Buenos Aires: Biblos-Fundación OSDE.

"Perón, J. D. (1948). "Mensaje pronunciado en el Instituto Bernasconi inaugurando el año lectivo el 29 de marzo de 1948". Presidencia de la Nación. Subsecretaría de Informaciones. Dirección General de Prensa.

" Ruffinelli, J. (1998). "Bajo cinco banderas: el cine multinacional de Carlos Hugo Christensen”. Nuevo Texto Crítico. 21/22, 277-325.

» Russo, E. (2005). "Cine y literatura. La bestia debe morir, Si muero antes de despertar, No abras nunca esa puerta. El thriller argentino: notas sobre tres casos extraños”. En: Clara Kriger (coord.), Cuadernos de cine argentino 6. Imágenes que tejen una red de textos. Buenos Aires: Instituto Nacional de Cine y Artes Audiovisuales, 59-80.

"Setton, R. (2010) “El crimen de Oribe, del policial fantástico al thriller naturalista". El matadero. Revista crítica de literatura argentina, 7, 63-83.

»Torres Ríos, L. (1952). La encrucijada (film)

» Torres Ríos, L. y Torre Nilsson, L. (1950). El crimen de Oribe (film).

»Viñoly Barreto, R. (1952). La bestia debe morir (film). 